\title{
NIR-Triggered Hyperthermal Effect of Polythiophene Nanoparticles Synthesized by Surfactant-Free Oxidative Polymerization Method on Colorectal Carcinoma Cells
}

\author{
Deval Prasad Bhattarai ${ }^{1}$ and Beom Su Kim ${ }^{2, *}$ \\ 1 Department of Chemistry, Amrit Campus, Tribhuvan University, Kathmandu 44613, Nepal; \\ devalprasadbhattarai@gmail.com \\ 2 Carbon Nano Convergence Technology Center for Next Generation Engineers (CNN), \\ Chonbuk National University, 567 Baekje-daero, Deokjin-gu, Jeonju-si 54896, Korea \\ * Correspondence: bskim@jbnu.ac.kr; Tel.: +82-63-270-4284
}

Received: 27 August 2020; Accepted: 16 September 2020; Published: 18 September 2020

\begin{abstract}
In this work, polythiophene nanoparticles (PTh-NPs) were synthesized by a surfactant-free oxidative chemical polymerization method at $60^{\circ} \mathrm{C}$, using ammonium persulphate as an oxidant. Various physicochemical properties were studied in terms of field emission scanning electron microscopy (FESEM), X-ray diffraction (XRD), Fourier transform infra-red (FT-IR) spectroscopy, and differential scanning calorimetry (DSC)/thermogravimetric analysis (TGA). Photothermal performance of the as-synthesized PTh-NPs was studied by irradiating near infra-red of $808 \mathrm{~nm}$ under different concentration of the substrate and power supply. The photothermal stability of PTh-NPs was also studied. Photothermal effects of the as-synthesized PTh-NPs on colorectal cancer cells (CT-26) were studied at $100 \mu \mathrm{g} / \mathrm{mL}$ concentration and $808 \mathrm{~nm}$ NIR irradiation of $2.0 \mathrm{~W} / \mathrm{cm}^{2}$ power. Our in vitro results showed remarkable NIR laser-triggered photothermal apoptotic cell death by PTh-NPs. Based on the experimental findings, it is revealed that PTh-NPs can act as a heat mediator and can be an alternative material for photothermal therapy in cancer treatment.
\end{abstract}

Keywords: polythiophene nanoparticles; chemical polymerization; photothermal; CT-26 cells; cancer treatment; apoptotic cell death

\section{Introduction}

Cancer is a worldwide problem and poses huge challenges to human health. Among the different types of body cancer, colorectal cancer is the third most common cancer, and the most common cause of cancer-related morbidity [1]. Colorectal cancer is a heterogeneous tumor with different genetic alterations, which is associated with some kinds of gut microbiota and mutations targeting oncogenes, tumor suppressor genes, and gene related to DNA repair mechanism [2,3]. If not cured in time, the metastatic colorectal cancer may also lead to peritoneal carcinomatosis [4].

To date, various routes have been developed for the treatment of cancer, which include chemotherapy, immunotherapy, radiotherapy, thermal ablation, surgery, and regional combined therapy $[5,6]$. A combination of oxaliplatin with 5-fluorouracil and a gold-based anticancer drug, such as auranofin, are being used as adjuvant chemotherapy for colon cancer treatment $[7,8]$. However, these modalities are less effective at addressing the case of metastasis. All in all, development of less aggressive and more effective therapies, compared to those of conventional ones, is necessary in the treatment of colorectal cancer. Since the last decade, cancer treatment by carcinoma cell ablation methods is attracting more research attention $[9,10]$. Radiofrequency ablation (RFA), microwave ablation (MWA), 
and laser ablation (LA) methods have been shown to be more effective in the cancer cell treatment by thermal ablation modality [11]. The ablation method offers benefit over conventional methods of cancer treatment, as it shows good local tumor control with minimum complication rates. This method outsmarts other common methods by avoiding the nuisances of multiple surgery in the case of metastasis. Furthermore, the thermal ablation method is attracting more interest, as it can be performed on an outpatient basis.

In this context, photothermal therapy could be an outstanding technique for cancer cell ablation, as it is regarded as a highly selective, minimally invasive, and remotely controllable thermal ablation technique [9]. For this purpose, near infra-red radiation of specified power is irradiated over the cancer cell adjunct with photothermal materials for a specified time of exposure. The first near infra-red (NIR) window falls in the range of 700-900 nm, which possesses effective tissue penetration ability, and can lead to selective cancer cell ablation in the presence of accumulated photothermal agents.

Previously, inorganic-based photothermal agents, such as CuS and Au NPs, were used for cancer cell ablation purpose. Study shows that metallic oxides or compounds are more likely to be toxic [12,13]. Later, researches on organic compound-based photothermal agents were reported. Such organic compound based photothermal agents are more tunable, and can be more functionalized, compared to inorganic-based photothermal agents. Currently, organic conjugated polymers, such as polypyrrole, polyaniline, and polythiophene and their derivatives, are gaining more preference to inorganic-based photothermal agents, due to their ease of synthesis, tunable surface functionality, and biocompatibility aspects $[14,15]$. In addition to chemical nature, geometry of nanomaterials also plays a crucial role in photothermal efficacy. Photothermal agents with higher surface area avail more irradiation space and exhibit higher thermal ablation efficacy upon NIR irradiation of specific power supply, and irradiation time over a specific concentration of nanomaterial concentration [9].

Among the various pre-requisites of a material to be used for biomedical applications, the aspect of biocompatibility is most important one. Some conjugated conductive polymers such as polyaniline, polypyrrole, polythiophene, etc. are reported to be biocompatible [16]. Among these polythiophene is least studied conductive polymer and its in vitro biocompatibility towards bone cells and nerve cells has been revealed [14]. In this context, this work has been focused to study the Polythiophene nanoparticle as a potential candidate for a photothermal agent.

Different routes of synthesis, including electrochemical, chemical, and enzymatic polymerization methods, have been reported for the synthesis of polythiophene [17-20]. PTh-NPs have been synthesized by cationic surfactant-assisted dilute polymerization of thiophene, using ferric chloride as an oxidant [21,22]. Jung et al. synthesized PTh-NPs via Fe ${ }^{+++} / \mathrm{H}_{2} \mathrm{O}_{2}$ catalyzed oxidative polymerization in aqueous medium [23]. Anionic surfactant-assisted and $\mathrm{Cu}$ (II) catalyzed oxidative polymerization of PTh-NPs in aqueous media showed the formation of spherical PTh-NPs [24]. Recently, coating of polythiophene onto the surface of gold by a biphasic liquid-liquid interfacial polymerization route has been reported $[25,26]$. In some cases, surfactant-assisted polymerization may add some doped ions onto polymer which, in some cases, may influence on material conductivity or in some other cases may induce some sorts of cytotoxicity. Under these considerations, we designed the synthesis of PTh-NPs without the use of surfactant. This process also enjoys the benefits of lessening the route of purification.

In this work, PTh-NPs were synthesized by oxidative chemical polymerization of thiophene in the presence of ammonium persulphate as an oxidant under surfactant-free condition. The photothermal effects of the as-synthesized PTh-NPs on colorectal cancer cells (CT-26) were studied at $100 \mu \mathrm{g} / \mathrm{mL}$ concentration and of NIR irradiation of $2 \mathrm{~W} / \mathrm{cm}^{2}$ power. The photothermal stability of PTh-NPs was also studied. 


\section{Materials and Methods}

\subsection{Materials}

Thiophene (purity $\geq 99 \%$ ), ammonium persulphate (purity $>98 \%$ ), and methanol (purity 99.5\%), ethanol (purity 95\%) were purchased from Sigma-Aldrich (St. Louis, MO, USA). Acetonitrile (purity $>99.5 \%$ ), was purchased from Samchun (Seoul, Korea). All the materials and reagents were of analytical grade, and were used as received, without any further purification.

\subsection{Preparation of Polythiophene Nanoparticles}

Polythiophene nanoparticles were synthesized according to our previously reported methods [27]. Briefly, $20 \mathrm{~mL}$ of semi molar ammonium persulphate solution was dropped into a vessel including $30 \mathrm{~mL}$ of semi molar $(\mathrm{M} / 2)$ thiophene solution in decimolar $(\mathrm{M} / 10)$ acetonitrile solution in aqueous media with constant stirring. The mixture of solution was heated at $60{ }^{\circ} \mathrm{C}$ with constant magnetic stirring at 300 relative centrifugal forces (RCF) for $24 \mathrm{~h}$. The solution was then taken out and allowed to settle for $12 \mathrm{~h}$ under ambient condition. Then it was washed with methanol, shaking in shaker each sample for half an hour followed by centrifugation at 5000 RFC for 10 min (Beckman Optima TM LE-80K, Beckman Inc., Brea, CA, USA). Then the supernatant solution was discarded keeping the solid residue in the tube. The process was repeated some more times. The thus obtained PTh substrate was first dried at room temperature (RT), and dried in vacuum drier for $6 \mathrm{~h}$ at $60{ }^{\circ} \mathrm{C}$. This PTh was used for characterization, and for various tests.

\subsection{Physico-Chemical Characterization}

The surface morphology and topography of the as-synthesized polythiophene was studied using Field-emission scanning electron microscopy (Zeiss SUPRA 40 VP FESEM, Cal Zeiss SMT Inc., Peabody, MA, USA) at an accelerating voltage of $5.0 \mathrm{kV}$. Particle dimensions were measured using Image J software (NIH, Bethesda, MD, USA) from different images of the same sample to obtain average dimension. The particle size distribution was determined by dynamic light scattering (DLS) analysis using Zetasizer ZS90 (Malvern Instruments Ltd., Malvern, UK). Biological Transmission electron microscopy (Bio-TEM, Hitachi H-7650, Hitachi, Tokyo, Japan) was used to inspect the morphology of the as-synthesized PTh-NPs under an accelerating voltage of $100 \mathrm{kV}$. For the TEM analysis, PTh-NPs were dispersed into ethanol solution152 one drop was casted over C-flat ${ }^{\mathrm{TM}}$ carbon grids (Electron Microscopy Science, Hatfield, PA, USA). X-ray diffraction (XRD) patterns were obtained using Rigaku X-ray diffractometer (Japan) with $\mathrm{Cu}-\mathrm{K} \alpha(\lambda=1.54 \AA)$ radiation over Bragg's angle (20) of (5-90) $)^{\circ}$. Polymerization of thiophene into polythiophene was studied using Spectrum GX Fourier transform infra-red (FT-IR) spectroscopy (PerkinElmer, Inc., Shelton, CT, USA). FT-IR spectra were measured in the range (4000-400) $\mathrm{cm}^{-1}$. Thermal stability of the as-synthesized PTh-NPs was studied using thermogravimetric analysis (TGA) and differential scanning calorimetry (DSC).

\subsection{Photothermal Properties of Polythiophene Nanocomposites}

Photothermal behavior of PTh-NPs was studied by recording the temperature increase of aqueous medium containing dispersed PTh-NPs $(100 \mu \mathrm{g} / \mathrm{mL})$ under the illumination of NIR laser $(808 \mathrm{~nm})$. The test was carried out by putting $1 \mathrm{~mL}$ PTh-NPs dispersed aqueous solution in 48-well plate, and it was subjected to NIR laser intensities of $2.0 \mathrm{~W} / \mathrm{Cm}^{2}$ for $5 \mathrm{~min}$, to study the power-dependent photothermal effects on the substrate. Real-time temperature changes exhibited by the sample were recorded by FLIR camera (FLIR Systems Pty Ltd, Sydney, Australia). Temperature change of water under NIR irradiation was taken as control. Photothermal stability was studied by recording the temperature change of the sample dispersed in aqueous solution over 10 cycles under the illumination of NIR radiation of $2.0 \mathrm{~W} / \mathrm{Cm}^{2}$ for $5 \mathrm{~min}$ NIR on, followed by $5 \mathrm{~min}$ NIR off. 


\subsection{Cell Culture}

Murine colorectal cancer cells (CT-26) were purchased from the American Type Collection (ATCC) and used for cancer cell model in this study. The cells were cultured in RPMI1640 (Thermo Fisher Scientific, Waltham, MA, USA) medium supplied with $10 \%$ fetal bovine serum (Thermo Fisher Scientific) and $1 \%$ antibiotics (Thermo Fisher Scientific) at $37^{\circ} \mathrm{C}$ under $5 \% \mathrm{CO}_{2}$. The cell culture medium was refreshed every 2 days during the experiment.

\subsection{Cytotoxicity}

Cell viability was determined by CCK- 8 assay. Briefly, the CT-26 cells $\left(5 \times 10^{3}\right)$ were seeded in 96-well culture plate and cultured overnight. Then NPs were added to each well at various final concentration of $(25,50,100,200$, and 500$) \mu \mathrm{g} / \mathrm{mL}$. After $24 \mathrm{~h}$ of cultivation, cells were washed with PBS. $20 \mu \mathrm{L}$ of CCK-8 kit (Sigma-Aldrich) solution and $200 \mu \mathrm{L}$ of RPMI 1640 cell culture medium (Thermo Fisher Scientific) were added to each well and incubated for $1 \mathrm{~h}$ at $37^{\circ} \mathrm{C}$. Plates were then analyzed with a microplate reader (Tecan Group Ltd., Salzburg, Austria) at $450 \mathrm{~nm}$.

\subsection{Cellular Uptake Assay}

To determine the cellular uptake of NPs, various concentrations of NPs were added to each well. After $4 \mathrm{~h}$ of cultivation, cells were washed with PBS 3 times, and fixed with $4 \%$ paraformaldehyde. The cells were then observed by microscopy (Eclipse Ts2-FL, Nikon, Tokyo, Japan).

\subsection{Hyperthermia Effects of $P T h-N P S$}

The CT-26 cells were seeded into 48-well plate and incubated for $24 \mathrm{~h}$. Then the PTh-NPs were added into each well at $100 \mu \mathrm{g} / \mathrm{mL}$ of final concentration of NPs for $4 \mathrm{~h}$. Next, CT-26 cells were exposed to an $808 \mathrm{~nm}$ laser $\left(2.0 \mathrm{~W} / \mathrm{cm}^{2}\right)$ for $5 \mathrm{~min}$ and incubated again for $24 \mathrm{~h}$. The viability was measured by CCK-8 assay. To confirm the viability, additional Live/dead staining assay was performed [9]. Briefly, after $24 \mathrm{~h}$ of cultivation, cells were rinsed with PBS and the Live/Dead ${ }^{\circledR}$ Viability/Cytotoxicity kit (Molecular Probe, Eugen, OR, USA) reagent solution was added. After incubation for $30 \mathrm{~min}$ in $\mathrm{CO}_{2}$ incubator at $37^{\circ} \mathrm{C}$, the cells were observed [28] using an inverted fluorescence microscope (Eclipse Ts2-FL).

\subsection{In Vitro Cell Apoptosis Analysis}

To determine if NIR triggered CT-26 apoptosis, CT-26 cells were seeded in 48-well plate at $1 \times 10^{4}$ per well and incubated with PTh-NPs. Cells were then irradiated with $808 \mathrm{~nm}$ laser $\left(2.0 \mathrm{~W} / \mathrm{cm}^{2}, 5 \mathrm{~min}\right)$. After incubation for another $24 \mathrm{~h}$, the cells were collected by trypsinization, and stained by Annexin V-FITC and PI, according to the manufacturer's protocol. To detect the apoptotic cells, flow cytometry (CytoFlex, Beckman, IL, Milan, Italy) were used at a $488 \mathrm{~nm}$. Laser was used to excite both dyes; the FL1 channel was used to collect the emission of Annexin V-FITC, and the FL2 channel was used to collect the emission of PI.

\subsection{Statistical Analysis}

All experiments were performed in triplicates. Values are expressed as mean \pm standard deviation. Statistical analysis was performed by one-way analysis of variance followed by Tukey-test using GraphPad Prism software (San Diego, CA, USA). $P<0.05$ was considered statistically significant.

\section{Results and Discussion}

\subsection{Physicochemical Characterization}

The general structure and surface morphology of the as-synthesized PTh-NPs were studied with the help of FESEM (Figure 1a). The imagery clearly reveals the spherical aggregation of PTh-NPs. 
The elemental analysis of PTh-NPs was carried out using energy-dispersive X-ray spectroscopy (EDX) (Figure 1b). The presence of carbon and sulphur in EDX mapping ensures that these elements are the constituents of PTh-NPs. The crystallinity of the as-synthesized PTh-NPs was studied in terms of $X$-ray diffraction imagery, which shows a low range of crystallinity. The particles size distribution and size of PTh-NPs were determined by DLS (Figure 1c) and Bio-TEM (Figure 1d) analyses. DLS results showed that the narrow size distribution of particles with average size of $\sim 69.8 \mathrm{~nm}$. In addition, the observed TEM image was consistent with particle size by DLS.

(a)

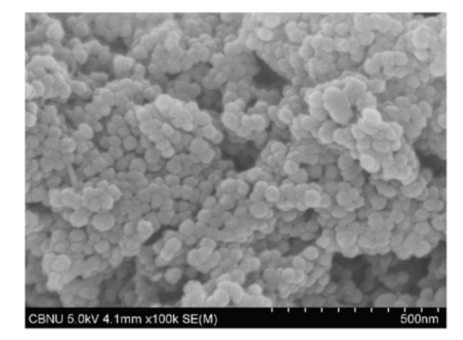

(c)

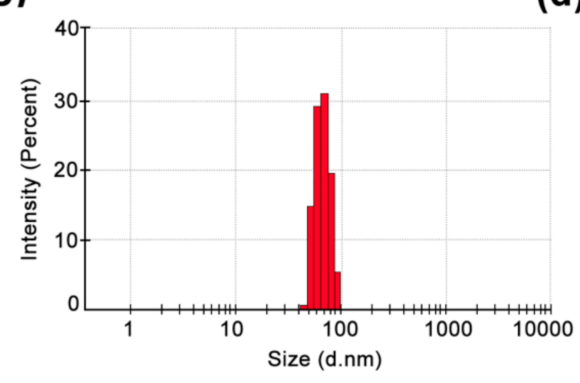

(b)

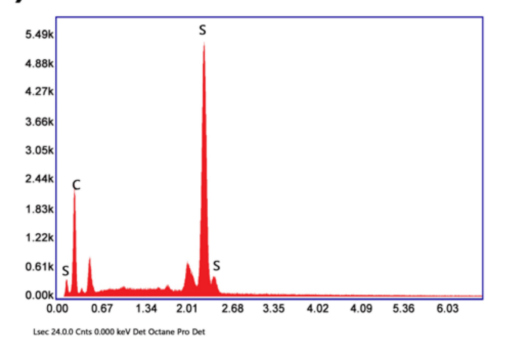

(d)

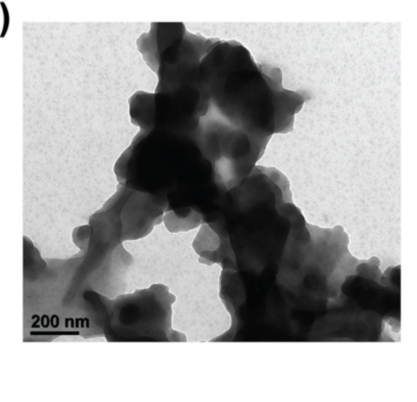

Figure 1. Physicochemical characterization of polythiophene particles. (a) FESEM image, and (b) EDX mapping of PTh-NPs, which shows the presence of $C$ and S elements, which are the constituent elements of polythiophene. Particles size dirstribution diagram by (c) DLS anaysis and (d) by Biological Transmission Electron Microscopy.

\subsection{Thermogravimetric (TGA) and Differential Scanning Calorimetry (DSC) Study}

Thermal behavior, like weight loss as a function of heat, residue content, and decomposition pattern of PTh-NPs, were studied in terms of thermogravimetric analysis (TGA) and differential scanning calorimetry (DSC). Around $96 \%$ mass retention was observed at about $200{ }^{\circ} \mathrm{C}$. Heating the substance above this temperature exhibited a significant amount of mass loss. At about $800{ }^{\circ} \mathrm{C}$, the residue content was around $36 \%$. These data show the significant thermal stability of the as-synthesized PTh-NPs for its biomaterial application, where the material is expected to withstand autoclaving temperature, though these are targeted to work at body temperature. The small quantity of mass loss of PTh-NPs at up to around $200^{\circ} \mathrm{C}$ could be associated with the loss of volatile impurities and inherent moisture (Figure 2a). The differential scanning curve (DSC) shows a glass transition temperature $\left(\mathrm{T}_{\mathrm{g}}\right)$ of $51{ }^{\circ} \mathrm{C}$. The endothermic peak in the DSC thermogram is observed at $257^{\circ} \mathrm{C}$. The $\mathrm{T}_{\mathrm{g}}$ value above room temperature signifies the rigid structural properties of the as-synthesized PTh-NPs (Figure $2 b$ ). 
(a)

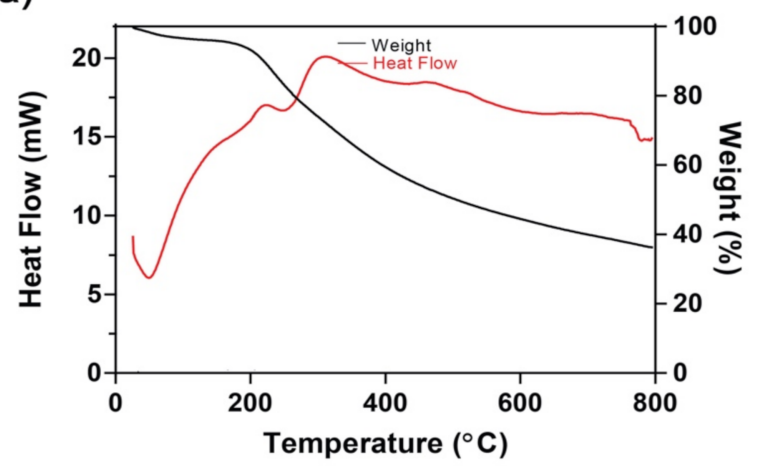

(b)

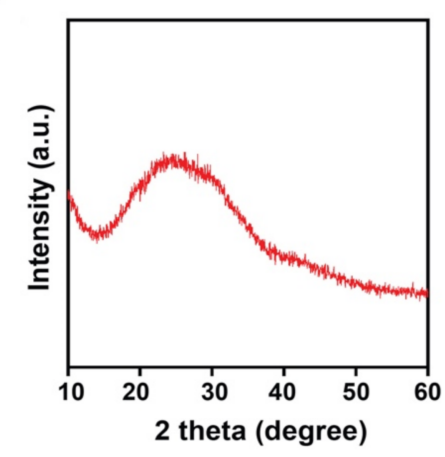

Figure 2. Characterization of PTh-NPs of (a) Thermogravimetric curve (wt. \% vs. temperature curve) and differential scanning curve (heat flow vs. temperature curve, and (b) X-ray diffraction.

\subsection{Photothermal Analysis and Photothermal Stability of PTh-NPS}

Photothermal therapy (PTT) is a physicochemical process, in which incident radiation falling onto some kinds of material results in an increase in temperature, a condition of hyperthermia. In the present study, near infra-red (NIR) of $808 \mathrm{~nm}$ wavelength was passed onto PTh-NPs dispersed in deionized water for specified period of time under different power supply, and the resulting temperature was noted. As a negative control, deionized water was used for photothermal study, where the resulting temperature was noted to be in the range $30-31^{\circ} \mathrm{C}$. As expected, the temperature was found to increase with the increase of irradiation power (Table 1) and (Figure 3a). Furthermore, the temperature was found to increase with increase in concentration of PTh-NPs dispersion under the same power irradiation (Table 1). For example, for the irradiation of $2.0 \mathrm{~W} / \mathrm{cm}^{2}$ NIR $808 \mathrm{~nm}$, the maximum temperature recorded for PTh-NP at $100 \mu \mathrm{g} / \mathrm{mL}$ and $200 \mu \mathrm{g} / \mathrm{mL}$ are $45.1^{\circ} \mathrm{C}$ and $49.4{ }^{\circ} \mathrm{C}$, respectively. The result shows that the increase in temperature is directly related to the concentration of the substrate. The temperature around or above $45^{\circ} \mathrm{C}$ is sufficient to ablate the cancerous cells by hyperthermia $[9,29]$, which can be obtained by tuning the substrate concentration and irradiation power.

Table 1. Photothermal ability of Polythiophene nanoparticles under the $808 \mathrm{~nm}$ NIR irradiation at different concentration.

\begin{tabular}{ccccc}
\hline \multirow{2}{*}{$\begin{array}{c}\text { Concentration of } \\
\text { PTh-NPs }(\mu \mathrm{g} / \mathbf{m L})\end{array}$} & \multicolumn{4}{c}{$\begin{array}{c}\text { Maximum Temperature }\left({ }^{\circ} \mathbf{C}\right) \text { Recorded under Different Power } \\
\text { Supply of NIR } \mathbf{8 0 8} \mathbf{~ n m} \text { for Different Concentration of Substrate }\end{array}$} \\
\cline { 2 - 5 } & $\mathbf{1 . 0 ~ W / \mathbf { c m } ^ { \mathbf { 2 } }}$ & $\mathbf{1 . 5 ~ W / \mathbf { c m } ^ { \mathbf { 2 } }}$ & $\mathbf{2 . 0} \mathbf{~ W} / \mathbf{c m}^{\mathbf{2}}$ & $\mathbf{2 . 5} \mathbf{~ W} / \mathbf{c m}^{\mathbf{2}}$ \\
\hline 100 & 35.0 & 39.2 & 45.1 & 53.5 \\
\hline 200 & 36.0 & 42.5 & 49.4 & 57.7 \\
\hline
\end{tabular}

(a)

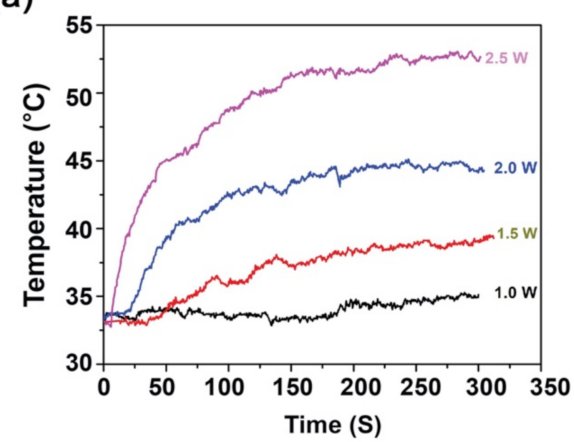

(b)

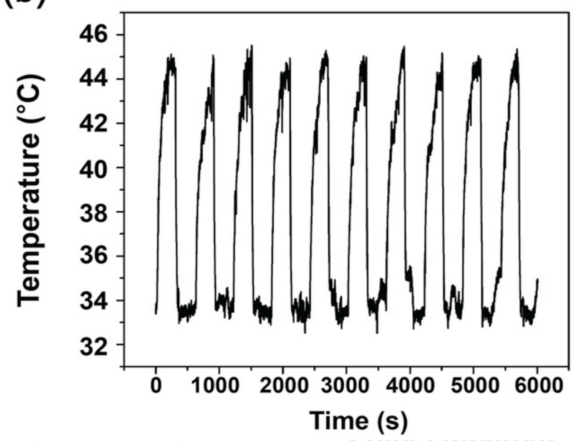

Figure 3. Photothermal study of PTh-NPs. (a) Photothermal performance of polythiophene nanocomposites, and (b) photothermal stability curve by real time temperature record for PTh-NPs, $100 \mu \mathrm{g} / \mathrm{mL}$, under irradiation of $2.0 \mathrm{~W} / \mathrm{cm}^{2}$. 
Photothermal stability is a very important aspect of material used for hyperthermia [30]. For this purpose, the photothermal stability of PTh-NPs was studied. PTh-NPs of $100 \mu \mathrm{g} / \mathrm{mL}$ concentration was taken, and was subjected to NIR $(808 \mathrm{~nm})$ irradiation for $5 \mathrm{~min}$ at power of $2.0 \mathrm{~W} / \mathrm{cm}^{2}$, followed by cooling for $5 \mathrm{~min}$ at RT. The cycle was repeated 10 times. The highest temperature recorded for these 10 cycles was almost constant, which confirms the substrate exhibits excellent photothermal stability (Figure 3b).

\subsection{In Vitro Cell Ablation Test}

Biocompatibility is the most important aspect while considering the nanoparticles for biomedical application [31]. Therefore, we first determined the effects of PTh-NPs on cell viability. CT-26 cells were incubated with PTh-NPs for $24 \mathrm{~h}$, and cell viability was evaluated. The results of CCK-8 assay showed that PTh-NPs are non-cytotoxic to CT-26 cells at $25-250 \mu \mathrm{g} / \mathrm{mL}$ concentration. But high concentration $(500 \mu \mathrm{g} / \mathrm{mL})$ of PTh-NPs exhibited little cytotoxicity (Figure $4 \mathrm{a})$. Crystal violet staining result (Figure $4 \mathrm{~b}$ ) was also consistent with the CCK-8 results. These results indicate that PTh-NPs in the range 25 to $250 \mu \mathrm{g} / \mathrm{mL}$ concentration were adaptable for further biomedical application.

(a)

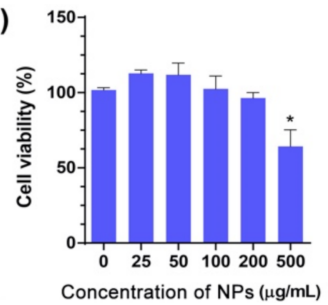

(b)

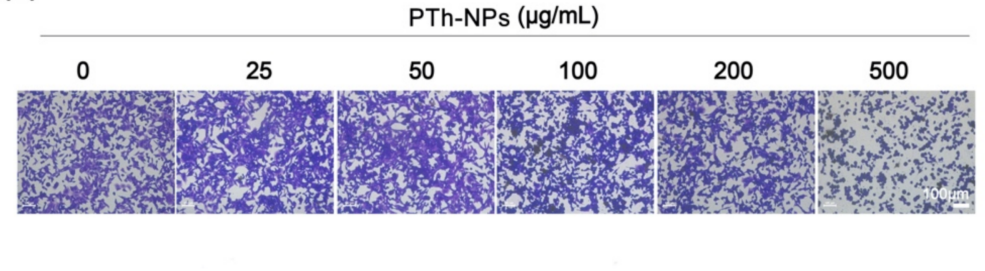

Figure 4. Cytotoxicity study of PTh-NPs. (a) Cell viability and (b) Crystal violet stained microscope images of CT-26 cell by treatment with PTh-NPs at concentration of $(25,50,100,200$, and 500) $\mu \mathrm{g} / \mathrm{mL}$. Each value is expressed as the mean \pm standard deviation. ${ }^{*} P<0.05$, when compared with the control.

After treatment with PTh-NPs for $3 \mathrm{~h}$, cellular uptake of PTh-NPs was characterized by dark-field microscopy (Figure 5a). The microscopy results showed that after the treatment with PTh-NPs, the PTh-NPs were scattered in the cytoplasm. Furthermore, the cellular uptake results indicated that the uptake of PTh-NPs also depended on the concentration of nanoparticles [32].

(a)

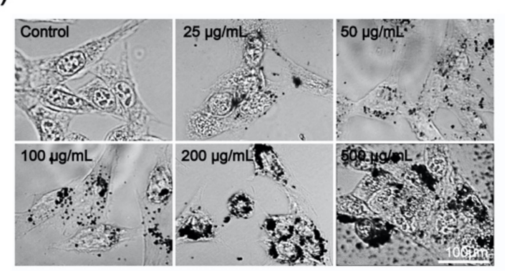

(b)

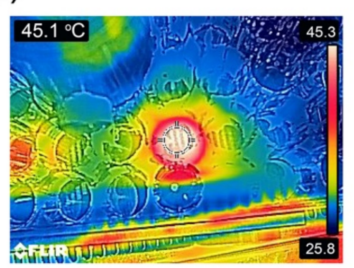

(c)

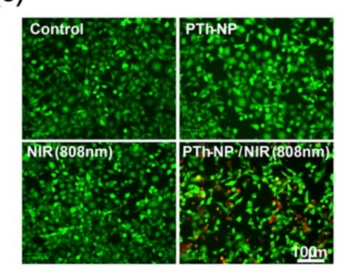

Figure 5. In vitro cellular uptake and photothermal effects of PTh-NPs. (a) Cellular uptake image of PTh-NPs in CT-26 cells using microscopy after $3 \mathrm{~h}$ of incubation. (b) Infrared photothermal image of PTh-NPs $(100 \mu \mathrm{g} / \mathrm{mL})$ dispersed in CT-26 cells culture media under $808 \mathrm{~nm}$ laser irradiation after $5 \mathrm{~min}$ at $2.0 \mathrm{~W} / \mathrm{cm}^{2}$. (c) Live/dead fluorescence images of PTh-NPs treated CT-26 cells with/without $808 \mathrm{~nm}$ laser irradiation $\left(2.0 \mathrm{~W} / \mathrm{cm}^{2}, 5 \mathrm{~min}\right)$.

To evaluate the NIR laser-triggered photothermal cancer cell ablation by PTh-NPs, the PTh-NPs treated CT-26 cells were exposed to irradiation for 5 min using an $808 \mathrm{~nm}$ laser at a power density of $2.0 \mathrm{~W} / \mathrm{cm}^{2}$ as an optimal condition. By treatment with $\mathrm{NIR}$, around $45.1{ }^{\circ} \mathrm{C}$ temperature was observed in the cell culture well that was incubated with PTh-NPs at $100 \mu \mathrm{g} / \mathrm{mL}$ (Figure 5b). Live/dead staining results showed that the number of dead cells (stained red) increased significantly for CT-26 cells that had been incubated with PTh-NPs. In contrast, from groups of CT-26 cells only, NIR irradiation only, and incubation with PTh-NPs only, very few dead cells were observed (Figure 5c). 
Furthermore, CCK-8 assay showed that the cell viability of CT-26 cells significantly decreased at a PTh-NPs treated cell by NIR irradiation photothermal ablation (Figure 6a). Next, we used flow cytometry analysis to evaluate the apoptotic cell death effect of PTh-NPs treated with laser irradiation by Annexin V-FITC/PI assay (Figure 6b,c). Phospholipids (PS) translocation of the outer layer of plasma membrane is a characteristic of the early phase of apoptosis. Annexin V has a high affinity for PS and therefore it is generally used to detect apoptotic cell death. However, Annexin V can also stain necrotic cells. Therefore, cells were double stained with propidium iodide (PI) to distinguish between the viable cells (Annexin $\mathrm{V}^{-} / \mathrm{PI}^{-}$) early apoptotic cells (Annexin $\mathrm{V}^{+} / \mathrm{PI}^{-}$), late apoptotic cells (Annexin $\mathrm{V}^{+} / \mathrm{PI}^{+}$), necrotic cells (Annexin $\mathrm{V}^{-} / \mathrm{PI}^{+}$) [33]. The FACS analysis result is shown in Figure 6b, the four-quadrant plots in each panel show the viable cells (lower left), early apoptotic cell (lower right), late apoptotic cells (upper right) and necrotic cells (upper left). The FACS analysis result showed more than $90 \%$ observed viable cells in the control, and only PTh-NPs treated groups. In only NIR treated group, a little amount late apoptotic cells (5.9\%) were detected. However, after $808 \mathrm{~nm}$ laser irradiation, the PTh-NPs treated cell groups showed the early apoptotic (23.62\%), late apoptotic cells $(23.76 \%)$ and necrotic cell death (13.8\%). The percentage of apoptotic/necrotic cells dramatically increased in PTh-NPs/NIR $808 \mathrm{~nm}$ group to compare other groups.

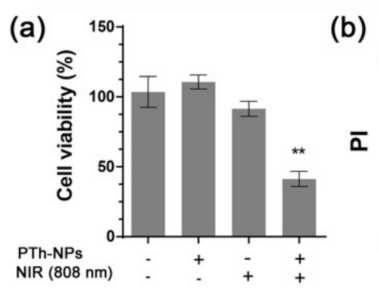

(b)

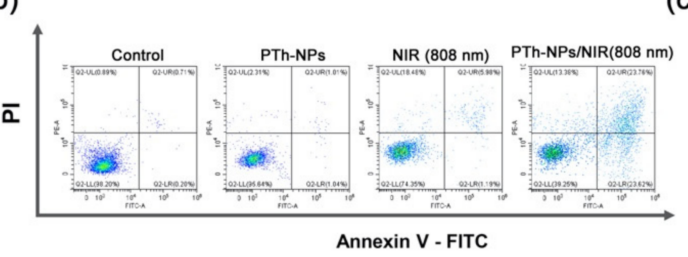

(c)

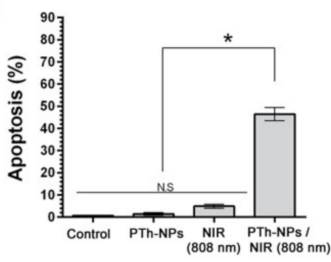

Figure 6. Photothermal effects of PTh-NPs on apoptotic cell death. (a) Cell viability of PTh-NPs $(100 \mu \mathrm{g} / \mathrm{mL})$ treated CT-26 cells with/without $808 \mathrm{~nm}$ laser irradiation $\left(2.0 \mathrm{~W} / \mathrm{cm}^{2}, 5 \mathrm{~min}\right)$ at $24 \mathrm{~h}$ of cultivation. (b) Flow cytometric analysis to determine cell death of CT-26 cells after PTh-NPs with/without NIR irradiation. (c) Percentage of apoptotic CT-26 cells. Each value is expressed as the mean \pm standard deviation. ${ }^{*} P<0.05$ and ${ }^{* *} P<0.01$, when compared to the control.

Hyperthermia can induce endoplasmic reticulum (ER) stress and result in apoptosis [34] in numerous cancers. In addition, hyperthermia induces reactive oxygen species (ROS) [35] and the functional disorders of the mitochondria [36]. Although the apoptotic molecular mechanism was not revealed in this study, our PTh-NP/NIR trigged apoptotic cell death is maybe related to ER stress and/or disorder of mitochondria function mechanism. Therefore, these results indicate that the PTh-NPs prepared by a surfactant-free oxidative polymerization method could be used as a heat mediator for the hyperthermia treatment of cancer cells.

\section{Conclusions}

In summary, we successfully prepared PTh-NPs by a surfactant-free oxidative polymerization method. The PTh-NPs exhibited photothermal effect under the NIR 808 irradiation. Furthermore, the as-synthesized PTh-NPs demonstrated good photothermal stability, which could be linked to the material stability for its destined application. In vitro cell viability cell showed that the as-synthesized PTh-NPs were non-cytotoxic to CT-26 cells at (25-250) $\mu \mathrm{g} / \mathrm{mL}$ concentration. NIR laser-triggered photothermal treatment of the cancer cells incubated with PTh-NPs showed increased number of dead cells, compared to those without PTh-NPs. The flow cytometry result showed that the PTh-NPs -treated cell groups showed a remarkable cell death effect. These results suggest a route for the use of PTh-NPs as a heat mediator for the hyperthermia treatment of cancer cells. Although in vivo experiments were not conducted in this study, it is generally known that nanoparticles pass through the wall of loosed blood vessel of cancer tissues and gets accumulated. Therefore, based on these findings, the PTh-NPs can be a good candidate for use as a composite material to induce and enhance 
further important and desired properties. Furthermore, bioactive molecules can be incorporated into such kinds of nanoparticles to enhance important properties, to induce novel properties that target biomedical applications. This finding suggests a promising research area of the use of conjugated polymeric nanomaterials in the field of biomedical applications. Further optimization, development, and extension of the present work would be considered in the continuation of this work in the near future.

Author Contributions: D.P.B. and B.S.K. conceived and designed the experiments; D.P.B. is participated in the review and editing of the manuscript; B.S.K. created the research design, conducted the experiments, analyzed the experimental results, and wrote the original draft of the manuscript. All authors have read and agreed to the published version of the manuscript.

Funding: This research was supported by the Basic Science Research Program under the National Research Foundation of Korea (NRF) and was funded by the Ministry of Education (NRF-2019R1I1A1A01057062).

Acknowledgments: In this section you can acknowledge any support given which is not covered by the author contribution or funding sections. This may include administrative and technical support, or donations in kind (e.g., materials used for experiments).

Conflicts of Interest: The author declares no conflict of interest.

\section{References}

1. Pal, I.; Rajesh, Y.; Banik, P.; Dey, G.; Dey, K.K.; Bharti, R.; Naskar, D.; Chakraborty, S.; Ghosh, S.K.; Das, S.K.; et al. Prevention of epithelial to mesenchymal transition in colorectal carcinoma by regulation of the E-cadherin- $\beta$-catenin-vinculin axis. Cancer Lett. 2019, 452, 254-263. [CrossRef]

2. Mármol, I.; Sánchez-De-Diego, C.; Pradilla-Dieste, A.; Cerrada, E.; Rodríguez-Yoldi, M. Colorectal Carcinoma: A General Overview and Future Perspectives in Colorectal Cancer. Int. J. Mol. Sci. 2017, 18, 197. [CrossRef] [PubMed]

3. Ganesh, K.; Stadler, Z.K.; Cercek, A.; Mendelsohn, R.B.; Shia, J.; Segal, N.H.; Diaz, L.A. Immunotherapy in colorectal cancer: rationale, challenges and potential. Nat. Rev. Gastroenterol. Hepatol. 2019, 16, 361-375. [CrossRef] [PubMed]

4. Sugarbaker, P.H.; Ryan, D.P. Cytoreductive surgery plus hyperthermic perioperative chemotherapy to treat peritoneal metastases from colorectal cancer: standard of care or an experimental approach? Lancet Oncol. 2012, 13, e362-e369. [CrossRef]

5. Ciardiello, D.; Vitiello, P.P.; Cardone, C.; Martini, G.; Troiani, T.; Martinelli, E.; Ciardiello, F. Immunotherapy of colorectal cancer: Challenges for therapeutic efficacy. Cancer Treat. Rev. 2019, 76, 22-32. [CrossRef] [PubMed]

6. Wang, Y.; Deng, W.; Li, N.; Neri, S.; Sharma, A.; Jiang, W.; Lin, S.H. Combining Immunotherapy and Radiotherapy for Cancer Treatment: Current Challenges and Future Directions. Front. Pharmacol. 2018, 9, 185. [CrossRef]

7. Gasiulè, S.; Dreize, N.; Kaupinis, A.; Ražanskas, R.; Čiupas, L.; Stankevicius, V.; Lesauskaitè, V.; Laurinavicius, A.; Valius, M.; Vilkaitis, G. Molecular Insights into miRNA-Driven Resistance to 5-Fluorouracil and Oxaliplatin Chemotherapy: miR-23b Modulates the Epithelial-Mesenchymal Transition of Colorectal Cancer Cells. J. Clin. Med. 2019, 8, 2115. [CrossRef]

8. Han, Y.; Chen, P.; Zhang, Y.; Lu, W.; Ding, W.; Luo, Y.; Wen, S.; Xu, R.; Liu, P.-P.; Huang, P. Synergy between Auranofin and Celecoxib against Colon Cancer In Vitro and In Vivo through a Novel Redox-Mediated Mechanism. Cancers 2019, 11, 931. [CrossRef]

9. Bhattarai, D.P.; Tiwari, A.P.; Maharjan, B.; Tumurbaatar, B.; Park, C.H.; Kim, C.S. Sacrificial template-based synthetic approach of polypyrrole hollow fibers for photothermal therapy. J. Colloid Interface Sci. 2019, 534, 447-458. [CrossRef]

10. Tiwari, A.P.; Bhattarai, D.P.; Maharjan, B.; Ko, S.W.; Kim, H.Y.; Park, C.H.; Kim, C.S. Polydopamine-based Implantable Multifunctional Nanocarpet for Highly Efficient Photothermal-chemo Therapy. Sci. Rep. 2019, 9, 2943. [CrossRef]

11. Vogl, T.J.; Zegelman, A.; Bechstein, W.O.; Zeuzem, S.; Zangos, S. Treatment of liver metastases of colorectal carcinoma: overview of hyperthermal ablation methods. Dtsch. Med. Wochenschr. (1946) 2013, 138, 792-798. 
12. Zhang, X.; Wu, J.; Williams, G.R.; Yang, Y.; Niu, S.; Qian, Q.; Zhu, L.-M. Dual-responsive molybdenum disulfide/copper sulfide-based delivery systems for enhanced chemo-photothermal therapy. J. Colloid Interface Sci. 2019, 539, 433-441. [CrossRef] [PubMed]

13. Mirrahimi, M.; Abed, Z.; Beik, J.; Shiri, I.; Dezfuli, A.S.; Mahabadi, V.P.; Kamrava, S.K.; Ghaznavi, H.; Shakeri-Zadeh, A. A thermo-responsive alginate nanogel platform co-loaded with gold nanoparticles and cisplatin for combined cancer chemo-photothermal therapy. Pharmacol. Res. 2019, 143, 178-185. [CrossRef] [PubMed]

14. Bhattarai, D.P.; Shrestha, S.; Shrestha, B.K.; Park, C.H.; Kim, C.S. A controlled surface geometry of polyaniline doped titania nanotubes biointerface for accelerating MC3T3-E1 cells growth in bone tissue engineering. Chem. Eng. J. 2018, 350, 57-68. [CrossRef]

15. Bhattarai, D.P.; Hwang, T.I.; Kim, J.I.; Lee, J.H.; Chun, S.; Kim, B.-S.; Park, C.H.; Kim, C.S. Synthesis of polypyrrole nanorods via sacrificial removal of aluminum oxide nanopore template: A study on cell viability, electrical stimulation and neuronal differentiation of PC12 cells. Mater. Sci. Eng. C 2020, 107, 110325. [CrossRef]

16. Rezk, A.I.; Bhattarai, D.P.; Park, J.; Park, C.H.; Park, C.H. Polyaniline-coated titanium oxide nanoparticles and simvastatin-loaded poly( $\varepsilon$-caprolactone) composite nanofibers scaffold for bone tissue regeneration application. Colloids Surf. B 2020, 192, 111007. [CrossRef]

17. German, N.; Popov, A.; Ramanaviciene, A.; Ramanavicius, A. Enzymatic Formation of Polyaniline, Polypyrrole, and Polythiophene Nanoparticles with Embedded Glucose Oxidase. Nanomaterials 2019, 9, 806. [CrossRef]

18. Osawa, S.; Ito, M.; Tanaka, K.; Kuwano, J. Electrochemical polymerization of thiophene under ultrasonic field. Synth. Met. 1987, 18, 145-150. [CrossRef]

19. Wei, Y.; Chan, C.C.; Tian, J.; Jang, G.W.; Hsueh, K.F. Electrochemical polymerization of thiophenes in the presence of bithiophene or terthiophene: kinetics and mechanism of the polymerization. Chem. Mater. 1991, 3, 888-897. [CrossRef]

20. Wang, J.; Neoh, K.G.; Kang, E.-T. Comparative study of chemically synthesized and plasma polymerized pyrrole and thiophene thin films. Thin Solid Films 2004, 446, 205-217. [CrossRef]

21. Gnanakan, S.R.P.; Rajasekhar, M.; Subramania, A. Synthesis of polythiophene nanoparticles by surfactant-assisted dilute polymerization method for high performance redox supercapacitors. Int. J. Electrochem. Sci. 2009, 4, 1289-1301.

22. Li, X.-G.; Li, J.; Huang, M.-R. Facile Optimal Synthesis of Inherently Electroconductive Polythiophene Nanoparticles. Chem. A Eur. J. 2009, 15, 6446-6455. [CrossRef] [PubMed]

23. Lee, S.J.; Lee, J.M.; Cheong, I.W.; Lee, H.; Kim, J.H. A facile route of polythiophene nanoparticles via Fe3+-catalyzed oxidative polymerization in aqueous medium. J. Polym. Sci. Part A Polym. Chem. 2008, 46, 2097-2107. [CrossRef]

24. Wang, Z.; Wang, Y.; Xu, D.; Kong, E.S.-W.; Zhang, Y. Facile synthesis of dispersible spherical polythiophene nanoparticles by copper(II) catalyzed oxidative polymerization in aqueous medium. Synth. Met. 2010, 160, 921-926. [CrossRef]

25. Inagaki, C.S.; Oliveira, M.M.; Zarbin, A.J. Direct and one-step synthesis of polythiophene/gold nanoparticles thin films through liquid/liquid interfacial polymerization. J. Colloid Interface Sci. 2018, 516, 498-510. [CrossRef]

26. Inagaki, C.S.; Oliveira, M.M.; Bergamini, M.F.; Marcolino-Junior, L.H.; Zarbin, A.J. Facile synthesis and dopamine sensing application of three component nanocomposite thin films based on polythiophene, gold nanoparticles and carbon nanotubes. J. Electroanal. Chem. 2019, 840, 208-217. [CrossRef]

27. Bhattarai, D.P.; Awasthi, G.P.; Maharjan, B.; Lee, J.; Kim, B.-S.; Park, C.H.; Kim, C.S. Synthesis of polythiophene nanoparticles by surfactant-free chemical oxidative polymerization method: Characterization, in vitro biomineralization, and cytotoxicity evaluation. J. Ind. Eng. Chem. 2019, 77, 243-252. [CrossRef]

28. Kim, B.-S.; Yang, S.-S.; Kim, C.S. Incorporation of BMP-2 nanoparticles on the surface of a 3D-printed hydroxyapatite scaffold using an $\varepsilon$-polycaprolactone polymer emulsion coating method for bone tissue engineering. Colloids Surf. B 2018, 170, 421-429. [CrossRef]

29. Strohbehn, J.W.; Douple, E.B. Hyperthermia and Cancer Therapy: A Review of Biomedical Engineering Contributions and Challenges. IEEE Trans. Biomed. Eng. 1984, 31, 779-787. [CrossRef] 
30. Bao, Z.; Liu, X.; Liu, Y.; Liu, H.; Zhao, K. Near-infrared light-responsive inorganic nanomaterials for photothermal therapy. Asian J. Pharm. Sci. 2016, 11, 349-364. [CrossRef]

31. Li, X.; Wang, L.; Fan, Y.; Feng, Q.; Cui, F.-Z. Biocompatibility and Toxicity of Nanoparticles and Nanotubes. J. Nanomater. 2012, 2012, 1-19. [CrossRef]

32. Isidoro, C.; Maneerat, E.; Giovia, A.; Carlo, F.; Caputo, G.; Ekkapongpisit, M.; Follo, C. Biocompatibility, endocytosis, and intracellular trafficking of mesoporous silica and polystyrene nanoparticles in ovarian cancer cells: effects of size and surface charge groups. Int. J. Nanomed. 2012, 7, 4147-4158. [CrossRef] [PubMed]

33. Crowley, L.C.; Marfell, B.J.; Scott, A.P.; Waterhouse, N.J. Quantitation of Apoptosis and Necrosis by Annexin V Binding, Propidium Iodide Uptake, and Flow Cytometry. Cold Spring Harb. Protoc. 2016, 2016, 087288. [CrossRef] [PubMed]

34. Shellman, Y.G.; Howe, W.R.; Miller, L.A.; Goldstein, N.B.; Pacheco, T.R.; Mahajan, R.L.; LaRue, S.M.; Norris, D.A. Hyperthermia Induces Endoplasmic Reticulum-Mediated Apoptosis in Melanoma and Non-Melanoma Skin Cancer Cells. J. Investig. Dermatol. 2008, 128, 949-956. [CrossRef] [PubMed]

35. Hou, C.-H.; Lin, F.-L.; Hou, S.-M.; Liu, J.-F. Hyperthermia Induces Apoptosis through Endoplasmic Reticulum and Reactive Oxygen Species in Human Osteosarcoma Cells. Int. J. Mol. Sci. 2014, 15, 17380-17395. [CrossRef]

36. Slimen, I.B.; Najar, T.; Ghram, A.; Debbabi, H.; Ben Mrad, M.; Abdrabbah, M. Reactive oxygen species, heat stress and oxidative-induced mitochondrial damage. A review. Int. J. Hyperth. 2014, 30, 513-523. [CrossRef]

(C) 2020 by the authors. Licensee MDPI, Basel, Switzerland. This article is an open access article distributed under the terms and conditions of the Creative Commons Attribution (CC BY) license (http://creativecommons.org/licenses/by/4.0/). 